\title{
Cervical spine fusion with bioabsorbable cages
}

\author{
Caleb R. Lippman, M.D., Michael HajJar, M.D., Bret Abshire, M.D., \\ George Martin, M.D., Robert W. Engelman, D.V.M., Ph.D., \\ AND DAVID W. CAHILl, M.D.
} Departments of Neurosurgery, and Pathology and Laboratory Medicine, College of Medicine,
University of South Florida, Tampa, Florida

\begin{abstract}
Object. Although it improves rates of fusion in surgical arthrodesis, conventional spinal instrumentation is associated with several risks, including hardware extrusion that injures adjacent anatomical structures, and disuse osteopenia as a result of stress shielding. The long-term effects of indwelling spinal instrumentation, although incompletely documented, may be detrimental. One way to avoid such problems would be to use bioabsorbable implantation devices. In this pilot study, performed in 1998 and 1999, the authors evaluated the use of a bioabsorbable interbody fusion device in a goat cervical spine model.

Methods. Forty-two goats underwent two-level anterior cervical discectomy and fusion: eight received iliac crest autograft; 16 received a cage implant composed of 70:30 poly(L-lactide-co-D,L-lactide)/polyglycolic acid (70:30 PLDLLA/PGA) filled with either autograft or recombinant human bone morphogenetic protein-2 (rhBMP-2); and 18 received a cage implant composed of 85:15 PLDLLA/PGA filled with either autograft or rhBMP-2. Animals were killed at 3, 6, and 12 months postsurgery, and their cervical spines were evaluated histologically, radiographically, and physically for fusion.

A primarily fibrous union was demonstrated in all animals killed at 3 months. At 6 months, bone trabeculae had become more prominent and the fibrous response less so in all cohorts. This occurred most frequently in the animals that underwent fusion with the 70:30 PLDLLA/PGA cages filled with rhBMP-2, in which 63\% attained a histologically confirmed union that contained quantitatively more bone and less fibrous tissue than in the other cohorts; $63 \%$ of the unions in the aforementioned cohort were graded quantitatively as being stable.

Conclusions. In this study the authors have established that the 85:15 PLDLLA/PGA cages are absorbed too quickly to be functionally useful in this model. The 70:30 PLDLLA/PGA cages worked as well as tricortical autograft when filled with cancellous autograft, and better when filled with rhBMP-2. At 6- and 12-month follow-up review, the 70:30 PLDLLA/PGA cages had not yet begun to be absorbed. There was little if any inflammatory response to these cages at 6 months. Future studies should include biomechanical and microradiographic testing, and a longer follow-up period is necessary in this model to determine when the 70:30 PLDLLA/PGA cages are absorbed.
\end{abstract}

\section{KEY WORDS • bioabsorbable implant • polylactic acid • polyglycolic acid • spinal fusion - cervical spine $\bullet$ goat}

Internal fixation has become an invaluable adjunct in spine surgery, allowing for rigid fixation, higher fusion rates, improved alignment, and faster mobilization of patients. ${ }^{3}$ Nonetheless, spinal instrumentation is not without risks. All instrumentation should be properly considered an adjunct to fusion, because all implants are subject to fatigue and will eventually fail if bone fusion has not been achieved. Short-term risks, such as malpositioning or injury to adjacent anatomical structures during implant placement, are applicable to all forms of spinal instrumentation.

Long-term risks are associated with all types of permanent indwelling hardware. Conventional spinal instrumen-

Abbreviations used in this paper: ANOVA = analysis of variance; PDLLA = poly-D,L-lactic acid; PGA = polyglycolic acid; PLA = polylactic acid; PLDLLA = poly (L-lactide-co-D,L-lactide); PLLA = poly-L-lactic acid; rhBMP-2 = recombinant human bone morphogenetic protein-2. tation is made of stainless steel or titanium alloys, and has a number of disadvantages in clinical usage. The implants' radiopacity makes evaluating fusion difficult, and makes some imaging modalities useless for clinical purposes. Because implants are foreign bodies, there is the persistent risk of infection. The great discrepancy between the elastic modulus of metal and cortical bone can lead to stress shielding of the spine, with the subsequent risk of telescoping, screw loosening, future instrumentation failure, device-related osteopenia, and possible fracture or instability. ${ }^{26,27,29}$ Also, particulate debris created by motion between metallic implants has been shown to lead to an inflammatory response in rabbit models of spinal fusion, and may theoretically be the cause of late-onset inflammation and osteolysis. ${ }^{13}$

Nonresorbable polymeric devices offer the advantages of radiolucency, and also possess an elastic modulus that is closer to but still higher than that of cortical bone. Thus, stress shielding remains a significant issue. Furthermore, 
the risk of particulate debris may be increased, and the long-term risks of a retained foreign body are still present.

To reduce these long-term risks, bioabsorbable spinal fixation devices are being developed. Biodegradable polymers were first used as internal fixation devices in 1966 for long-bone fractures, ${ }^{23}$ and have been in use for more than 30 years in the form of surgical sutures. ${ }^{22,23}$ These materials are now used in orthopedic procedures for fracture fixation, ${ }^{7,18,19}$ for osteotomy stabilization, as interference screws in anterior cruciate ligament reconstruction,,$^{33}$ to reconstruct the skull base, ${ }^{21}$ and as plates in neurosurgical ${ }^{31,32}$ and maxillofacial procedures. ${ }^{10,11}$ These polymers are now being investigated for use in the spine. $2,3,15,20,24,30,34-36,40,41$

Like permanent implants, bioabsorbable ones are designed to provide immediate support to the weight-bearing portions of the spine, as well as to provide support for osteoconductive and osteogenic grafts, so that a durable fusion can occur. While fusion is taking place, the implants are absorbed by the body and lose strength. An increasing load is placed on the autograft, preventing stress shielding. Bioabsorbable polymers are initially radiolucent, and because the implants ultimately will be resorbed, in the long term there will be no stress shielding, no particulate debris, and no retained foreign body.

Most research has involved implants made of combinations of the alphapolyesters PLA and PGA and their stereoisomers, which are all resorbed in the body and ultimately excreted as carbon dioxide and water. There are several stereoisomers of PLA available for use: PLLA characteristically has a higher crystallinity, strength, and longer periods of degradation than a second stereoisomer, PDLLA, which has lower strength and faster rates of degradation. ${ }^{2}$ The strength and absorbability of the copolymer can be significantly altered by the ratio of these two forms. These two isomers have been combined in a 70-30 ratio of PLLA to PDLLA, whose strength and degradation rate are intermediate between PLLA and PDLLA. ${ }^{2}$ This copolymer has been studied experimentally and has been found to reduce dural adhesions after laminotomy in sheep and $\operatorname{dogs},^{40}$ to provide adequate strength and fusion as interbody spacers in sheep ${ }^{34,41}$ and goat ${ }^{38}$ lumbar spine, and to prevent soft-tissue ingrowth and allow for increased bone growth when used for iliac crest reconstruction after removal of a bone wedge. ${ }^{12}$ In human cadaveric spines, this polymer has been shown to reduce lumbar spinal motion when used as an anterior plate with titanium cages compared with cages implanted without the plate, ${ }^{15}$ and, when augmented with an expandable poly(propylene glycol-cofumaric acid) foam scaffold, it was found to be as strong as titanium cages. ${ }^{20}$

The copolymer 70:30 PLa has been used clinically in humans as an interbody spacer in transforaminal lumbar interbody fusion ${ }^{24}$ and posterior lumbar interbody fusion, ${ }^{6}$ and as absorbable anterior plates after anterior cervical discectomy and fusion. ${ }^{36}$ Although the follow-up duration is short, no patient has experienced graft migration or other complications to suggest that they are not recovering as well as patients treated with standard hardware.

There are several points to consider in the design of biodegradable cages for the spine. 1) The resorption rate is dependent on numerous variables, including the device's surface/volume ratio; the local tissue environment's $\mathrm{pH}$, temperature, and vascularity; and the particular stereochemistry and chemical composition of the implants. 2) The functional degradation rate of the implant (the decrease in its strength over time) must be considered with respect to the time it takes for a successful arthrodesis to occur, and the surface area of the fusion. 3) The presence and intensity of any inflammatory response must be considered. 4) Finally, as biodegradable devices are resorbed, does the volume they once occupied ever become filled in by bone or inflammatory tissue? If so, the time at which this occurs should be recognized. If not, then even an initially successful fusion may fail because of less than optimal bone contact.

In general, PLA copolymers degrade over a longer period of time and produce less inflammatory reaction than PGA alone. Nevertheless, in products made of both copolymers, as the relative amount of PLA increases the degradation time decreases. An implant can be tailored to degrade in a time period appropriate for the specific fusion application. ${ }^{16}$

This study was completed in 1998 and 1999, and predated more recent works conducted using off-the-shelf polymers originally designed for use in nonweight-bearing applications such as craniofacial reconstruction. The questions we wanted to address with this study included the following. 1) What is the rate of resorption of two different copolymers composed of different ratios of PLDLLA and PGA? 2) Would bone grow despite the acidic breakdown products? 3) Would there be a significant inflammatory response to the devices or their breakdown products? 4) Would rhBMP-2 function in the presence of the acidic breakdown products?

\section{MATERIALS AND METHODS}

\section{Experimental Animals}

Fifty-four adolescent (1-2 years old) male goats underwent a two-level anterior cervical discectomy and fusion. All animals were cared for in a program accredited by the Association for the Assessment and Accreditation of Laboratory Animal Care International. This protocol was in compliance with the regulations established by the Institutional Animal Care and Use Committee of the University of South Florida.

\section{Randomization of Animals}

Each animal was randomly assigned to one of several cohorts. The control animals underwent a two-level anterior cervical discectomy and fusion with a tricortical iliac crest autograft; the others underwent fusion with either an 85:15 or 70:30 PLDLLA/PGA cage, which was in turn filled with either small fragments of fresh autograft or rhBMP-2.

\section{Surgical Procedure}

The animals were not allowed to eat for 24 hours before surgery; they were allowed to drink water freely. Antibiotic prophylaxis with $1 \mathrm{~g}$ cefazolin was administered intravenously to each goat before surgery. 
Anesthesia was induced intravenously with $0.05 \mathrm{mg} / \mathrm{kg}$ atropine, $4 \mathrm{mg} / \mathrm{kg}$ ketamine, and $0.05 \mathrm{mg} / \mathrm{kg}$ xylazine. All animals were intubated, and anesthesia was maintained with 1 to $2 \%$ isoflurane mixed with room air.

The animals were placed prone, and the posterior superior iliac crest shaved, prepared with alcohol and betadine, and draped in a sterile fashion. In the eight control animals, a $1 \times 2-\mathrm{cm}$ tricortical iliac bone autograft was obtained; in the other 34 animals, approximately $4 \mathrm{~cm}^{3}$ of cancellous iliac crest bone was harvested to fill the cages. The iliac crest wound was closed in a multilayered fashion; no drains were used.

Each animal was then placed supine, and the anterior neck was shaved, prepared, and draped in a sterile manner. A longitudinal skin incision was made on the right side, and the standard anterolateral approach to the cervical spine was used, developing the plane with the sternocleidomastoid and carotid sheath laterally and the trachea and esophagus medially. The longus colli muscle was divided in the midline with monopolar cautery. The anterior aspects of the C2-3 and C3-4, C3-4 and C4-5, or C4-5 and C5-6 disc spaces were exposed. The anterior two thirds of the two exposed disc spaces were removed with a combination of curettes and rongeurs; no attempt was made to remove the posterior longitudinal ligament or to enter the spinal canal. Care was taken to remove the cartilaginous endplate and to decorticate partially both the superior and inferior bone endplates.

The copolymer cages were each packed with approximately $2 \mathrm{~cm}^{3}$ of cancellous bone autograft or rhBMP-2 and inserted into a slightly distracted interspace with the convex side facing posteriorly. Each wedge-shaped tricortical iliac bone autograft was similarly tamped into an interspace, with the cancellous side facing posteriorly. No internal fixation devices were used. The surgical sites were irrigated with sterile normal saline and closed in multiple layers in routine fashion. Animals received $0.005 \mathrm{mg} / \mathrm{kg}$ buphrenorphine intramuscularly to alleviate postoperative pain. The goats were fed freely, observed in a cage for 24 hours postoperatively, and then allowed to rejoin the herd. Animals were maintained without an orthosis and unrestricted activity was permitted. All goats quickly returned to normal activity and social interactions, including head butting.

Radiographs were obtained immediately after and at 1 , 6,12 , and 24 weeks postsurgery. Animals received intravenous sedation with Versed before each radiograph, and were returned to the herd that day if not killed. Animals were sedated and humanely killed at 3,6 , or 12 months by intravenous administration of $80 \mathrm{mg} / \mathrm{kg}$ pentobarbital.

\section{Interbody Device}

The raw polymers 85:15 and 70:30 PLDLLA/PGA were commercially obtained and extruded into rods. The rods were milled to yield interbody devices that approximated the anterior, lateral, and vertical interbody space of the goat cervical spine. The anterior-posterior dimension was $12 \mathrm{~mm}$, the maximum width was $15 \mathrm{~mm}$, the anterior height $8 \mathrm{~mm}$, and the posterior height $6 \mathrm{~mm}$. A central 6$\mathrm{mm}$ hollow chamber with four peripheral 1- to 2-mm hollow chambers were created for the bone autograft (Fig. 1).
All cages were sterilized with gamma irradiation before implantation.

\section{Manual Stress Analysis}

At 3, 6, and 12 months postoperatively, the animals were killed and their cervical spines were excised en bloc, removing all muscle but taking care to preserve all ligaments. Each spine was manually stressed by two observers who were blinded to the surgical procedure to assess the degree of motion at each of the treated interspaces compared with adjacent untreated interspaces. Each interspace was scored (Table 1) and assigned a grade of 2 if
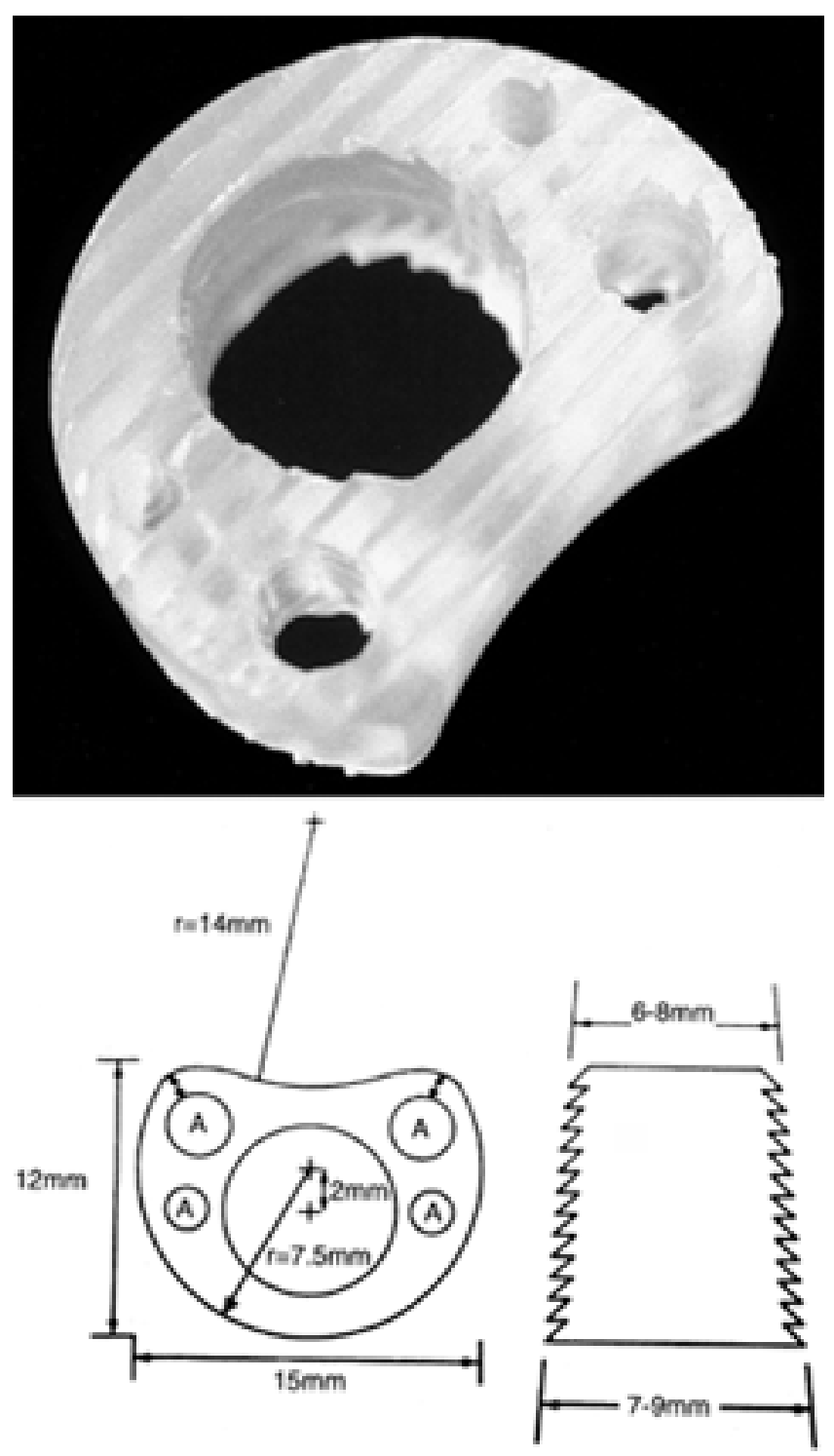

Fig. 1. Photograph (upper) and schematic drawing (lower) of the PLDLLA/PGA interbody fusion cages prior to implantation. The cages were designed to match the shape of the goat subaxial cervical discs. One large central and four peripheral hollows were packed with autologous cancellous bone or rhBMP-2 prior to implantation. 
TABLE 1

Scale used to grade the interspaces in goats treated with bioabsorbable devices

\begin{tabular}{|c|c|}
\hline Analysis \& Grade* & Description of Grade \\
\hline \multicolumn{2}{|l|}{ manual stress } \\
\hline 0 & typical joint flexion-extension mobility \\
\hline 1 & reduced joint flexion-extension mobility \\
\hline 2 & rigidity, little to no joint flexion-extension mobility \\
\hline \multicolumn{2}{|l|}{ radiographic } \\
\hline 0 & no intervertebral or transvertebral osseous densities \\
\hline 1 & $\begin{array}{l}\text { fragmented intervertebral or transvertebral osseous } \\
\text { densities }\end{array}$ \\
\hline 2 & transvertebral osseous bridge \\
\hline \multicolumn{2}{|l|}{ histological } \\
\hline 0 & no evidence of new bone formation \\
\hline 1 & $\begin{array}{l}\text { fibrosis, osteoblast proliferation, minor new ossifi- } \\
\text { cation }\end{array}$ \\
\hline 2 & $\begin{array}{l}\text { mod, new, fibroendochondral ossification, } \\
\text { partial fibrocartilaginous bridge }\end{array}$ \\
\hline 3 & $\begin{array}{l}\text { fusion, fibrocartilaginous bone union to identifi- } \\
\text { able bone bridge }\end{array}$ \\
\hline
\end{tabular}

* The three scores were added; a composite grade of 7 was judged to be a stable union.

rigid with no detectable flexion-extension motion, 1 if reduced in motion but not rigid, or 0 if typical in flexion-extension motion compared with adjacent untreated interspaces. A researcher not involved with the surgical procedures evaluated the spines manually. Because this was a pilot feasibility study, simple physical examination was used to stress the spinal segments. Any research in which it is concluded that such a device is suitable for human testing would require detailed biomechanical analysis of the implants in both in vivo and in vitro settings.

\section{Radiographic Analysis}

Radiographs obtained immediately before planned death were scored (Table 1) by an observer blinded to treatment group, and each interspace was assigned a grade of 2 if a transvertebral osseous bridge was present, 1 if new fragmented osseous densities were evident, or graded 0 if no osseous densities had formed. A researcher not involved with the surgical procedures evaluated the radiographs.

\section{Histological Analysis}

An observer working in a blinded fashion grossly examined the excised cervical spine of each animal. Each spine was then cut along the coronal plane, beginning on the ventral surface, and fixed in $10 \%$ neutral buffered formalin. To aid in subgroup examination, one fused interspace obtained in a single animal from each of the two experimental groups was divided along the sagittal plane, beginning on the right lateral side. Whenever subgross sectioning revealed cage remnants or degradation debris, their position was noted. After fixation, each treated interspace was trimmed, decalcified, and embedded in paraffin. Contiguous thin sections were stained with $\mathrm{H} \& \mathrm{E}$. Specimens were examined qualitatively to assess the extent of growth of new trabecular bone from each end- plate, remodeling of the bone autograft, and presence of residual polymeric debris or inflammatory cells. Each interspace was scored histologically (Table 1) based on the degree of new bone formation. A grade of 3 was assigned if a marked amount of newly formed bone was present, 2 if a moderate amount was present (Fig. 2 left), 1 if minor new bone was present (Fig. 2 right), or 0 if no new bone had formed.

\section{Composite Grade}

The three grades assigned according to the manual strength, radiographic, and histological analyses were added for each level. An interspace with a manual stress grade of 2, a radiographic grade of 2, and a histological grade of 3 received a composited grade of 7 , which was judged to be a stable union. The histological nature of that union (fibrous compared with bone tissue) and the accompanying complications were noted for each interspace.
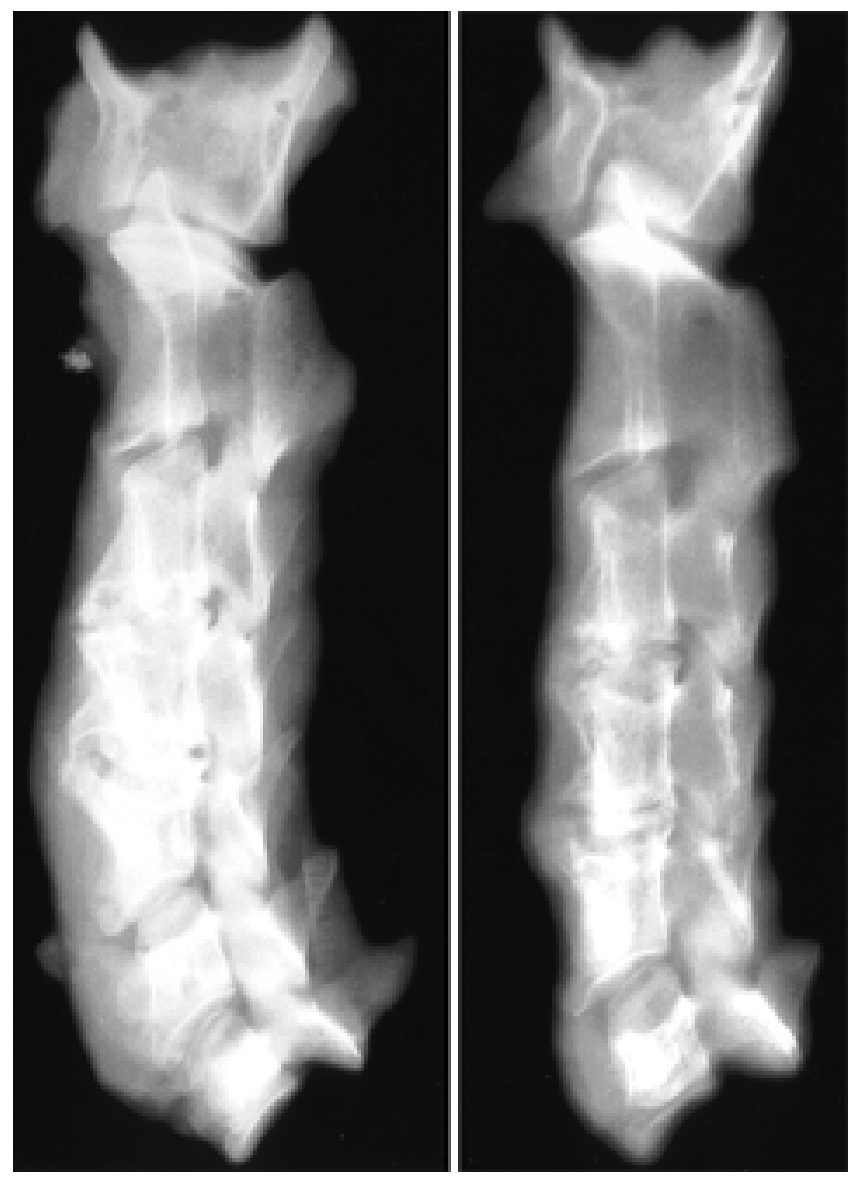

Fig. 2. Postoperative radiographs obtained in two goats killed at 6 months. Left: This goat received 70:30 PLDLLA/PGA cages filled with rhBMP-2 at C3-4 and C4-5. There is solid bone connecting the vertebrae, and both interspaces were assigned a grade of 2. Right: This goat also underwent fusion with 70:30 cages filled with rhBMP-2 at C3-4 and C4-5. There is new bone growth from both endplates at the C3-4 and C4-5 interspaces, but no bone bridges connect the endplates; these levels were assigned grades of 1 . 


\section{RESULTS}

All animals that underwent the surgical procedure experienced no neurological, infectious, or other sequelae. All goats were standing, ambulating, and had resumed eating within 24 hours of surgery. There were no clinical indications of local or systemic infection, nor was there any behavior consistent with pain or discomfort after the first 24 hours postoperatively. All animals resumed normal activities once returned to the herd, including head butting and jumping. All statistics were calculated using a personal computer running commercially available software (The Statistics Calculator; StatPac, Inc., Minneapolis, $\mathrm{MN})$.

\section{Gross Evaluation}

Neither solid cages nor functional remnants (long fragments that were still in contact and embedded in both superior and inferior vertebrae) of the 85:15 PLDLLA/PGA cage were present at 3 or 6 months postimplantation. The 70:30 PLDLLA/PGA cage showed no signs of absorption or degradation at either 3 or 6 months, and appeared to be intact in all specimens. No remnants of either cage were found anterior to the vertebrae, indicating that there were no cage extrusions. A similar finding was noted in four animals followed for 12 months after placement of a 70:30 cage filled with rhBMP-2 (no other group of animals was studied for 12 months).

Gross inflammatory debris was found around the 85:15 PLDLLA/PGA cages at 3 months; less debris was qualitatively present at 6 months. Minimal inflammatory debris was present around the 70:30 PLDLLA/PGA cages at 3 months, and none was found at 6 months. There was no gross evidence of inflammation or granuloma formation in the control animals. We found no evidence of overt or gross inflammation or fibrous adhesions in the soft tissues of the neck or in the perivertebral area in any animal.

\section{Manual Stress Analysis}

Each cervical spine was manually stressed, and the treated levels were compared with untreated, intact levels. All values are given as the mean \pm standard error of the mean. At 3 months, the control spines were assigned a grade of $1.1 \pm 0.4$ (seven interspaces in four goats); the spines treated with 85:15 PLDLLA/PGA cages containing autograft and rhBMP-2 were graded $0.9 \pm 0.6$ (10 interspaces in five goats) and $1.3 \pm 0.5$ (eight interspaces in four goats), respectively; the spines treated with 70:30 PLa cages filled with autograft (four interspaces in two goats) and rhBMP-2 (eight interspaces in four goats) were all graded $1 \pm 0$. (Table 2 ). There were no significant differences between the five animal cohorts. All spines exhibited more stiffness compared with an untreated interspace, although with some residual flexion and extension.

As detailed in Table 3, at 6 months, the control spines were assigned a grade of $0.9 \pm 1$ (seven interspaces in four goats); the spines treated with 85:15 PLDLLA/PGA cages were graded $1.3 \pm 0.7$ when the device was filled with autograft (10 interspaces in five goats), and $0.8 \pm 1.5$ when it was filled with rhBMP-2 (eight interspaces in four goats); the spines treated with 70:30 cages were graded $0.4 \pm 0.5$ when the device was filled with autograft (eight
TABLE 2

The mean grades in the goats killed 3 months after treatment*

\begin{tabular}{|c|c|c|c|c|}
\hline \multirow[b]{2}{*}{ Cohort } & \multicolumn{4}{|c|}{ Grade } \\
\hline & Manual Stress & Radiographic & Histological & Composite \\
\hline $\begin{array}{l}\text { controls } \\
\text { (7 ISs) }\end{array}$ & $1.1 \pm 0.4$ & $0.9 \pm 0.7$ & $1.3 \pm 0.8$ & $3.3 \pm 1.7$ \\
\hline $\begin{array}{c}85: 15 \text { cages } \\
\text { w/ autograft } \\
\text { (10 ISs) }\end{array}$ & $0.9 \pm 0.6$ & $1.3 \pm 0.5$ & $1.6 \pm 0.7$ & $3.8 \pm 1.5$ \\
\hline $\begin{array}{c}\text { w/ rhBMP-2 } \\
\text { (8 ISs) }\end{array}$ & $1.3 \pm 0.5$ & $0.6 \pm 0.5$ & $1.3 \pm 0.5$ & $3.1 \pm 1.3$ \\
\hline $\begin{array}{l}\text { 70:30 cages } \\
\text { w/ autograft } \\
\text { w/ rhBMP-2 }\end{array}$ & $\begin{array}{l}1.0 \pm 0.0 \\
(4 \mathrm{ISs}) \\
1.0 \pm 0.0\end{array}$ & $\begin{array}{c}1.1 \pm 0.4 \\
(8 \mathrm{ISs}) \\
1.4 \pm 0.5\end{array}$ & $\begin{array}{l}1.2 \pm 0.5 \\
(8 \mathrm{ISs}) \\
1.4 \pm 0.5\end{array}$ & $\begin{array}{l}3.8 \pm 1.0 \\
(4 \mathrm{ISs}) \\
3.8+0.9\end{array}$ \\
\hline $\begin{array}{c}\text { w/ rhBMP-2 } \\
\text { (8 ISs) }\end{array}$ & $1.0 \pm 0.0$ & $1.4 \pm 0.5$ & $1.4 \pm 0.3$ & $3.8 \pm 0.9$ \\
\hline
\end{tabular}

* There were no significant differences between cohorts. All values are given as the mean \pm standard error of the mean. Abbreviation: IS = interspace.

interspaces in four goats), and $1.8 \pm 0.5$ when it was filled with rhBMP-2 (eight interspaces in four goats). The spines treated with 70:30 PLa cages filled with rhBMP-2 were found to be significantly stronger $(\mathrm{p}<0.05$, ANOVA) than all spines except for those treated with $85: 15$ cages filled with autograft. Furthermore, the spines treated with 70:30 cages filled with autograft were significantly weaker than spines treated with 70:30 cages filled with rhBMP-2, as were those treated with 85:15 cages filled with autograft (Table 3).

\section{Radiographic Evaluation}

New intervertebral osseous densities (Grade 1 or 2 ) were present in five of seven control animals at 3 months, for a mean grade of $0.9 \pm 0.7$ (seven interspaces); the grades for the $85: 15$ cages with autograft and rhBMP-2 were $1.3 \pm 0.5$ (10 interspaces) and $0.6 \pm 0.5$ (eight inter-

TABLE 3

The mean grades in the goats killed 6 months after treatment

\begin{tabular}{ccccc}
\hline \hline & \multicolumn{4}{c}{ Grade } \\
\cline { 2 - 5 } Cohort & Manual Stress & Radiographic & Histological & Composite \\
\hline $\begin{array}{c}\text { controls } \\
\text { (7 ISs) }\end{array}$ & $0.9 \pm 1.0$ & $1.3 \pm 0.5$ & $1.4 \pm 0.8$ & $3.7 \pm 2.1$ \\
$\begin{array}{c}85: 15 \text { cages } \\
\text { w/ autograft } \\
\text { (10 ISs) } \\
\text { w/ rhBMP-2 } \\
\text { (8 ISs) }\end{array}$ & $0.8 \pm 1.5 \pm 0.7$ & $1.3 \pm 0.8$ & $2.0 \pm 0.8$ & $4.6 \pm 2.2$ \\
$\begin{array}{c}70: 30 \text { cages } \\
\text { w/ autograft } \\
\text { (8 ISs) } \\
\text { w/ rhBMP-2 } \\
\text { (8 ISs) }\end{array}$ & $0.4 \pm 0.5$ & $1.3 \pm 0.5$ & $1.6 \pm 0.5$ & $3.9 \pm 1.1$ \\
\hline
\end{tabular}

* The histological and composite grades of the 70:30 PLDLLA/PGA cages filled with rhBMP-2 were significantly $(\mathrm{p}<0.05)$ higher than those of the other cohorts, except for the 85:15 cages filled with autograft. See text for details. 
spaces), respectively. The grades in levels fused with 70:30 cages filled with autograft or rhBMP-2 were $1.1 \pm$ 0.4 (eight interspaces) and $1.4 \pm 0.5$ (eight interspaces), respectively. The spines treated with 85:15 cages filled with rhBMP-2 showed significantly less radiographically confirmed fusion than spines treated with 85:15 cages filled with autograft, or those treated with 70:30 cages filled with rhBMP-2 ( $p<0.05$, ANOVA). There were no other significant differences between cohorts (Table 2).

At 6 months, the mean radiographic grade in the control cohort was $1.3 \pm 0.5$ (seven interspaces). The grades in the $85: 15$ cohorts with autograft and rhBMP-2 averaged $1.3 \pm 0.8$ (10 interspaces) and $1.5 \pm 0.5$ (eight interspaces). The mean radiographic grades in the groups treated with 70:30 devices filled with autograft or rhBMP-2 were $1.3 \pm 0.5$ and $1.9 \pm 0.4$ (eight interspaces in each cohort), respectively (Table 3 ).

Although the mean radiographic grades were comparable in all groups, as expected, these grades were higher in animals examined at 6 months. Furthermore, in all animals but one in the cohort that underwent fusion with the 70:30 PLDLLA/PGA cage and rhBMP-2, the radiographic grade was 2 , meaning that the fusion mass crossed the interspace. Osseous bars were seen both within and anterior to the cage in this goat. The group treated with 70:30 cages and rhBMP-2 demonstrated significantly more radiographically confirmed fusion than those treated with 85:15 cages containing autograft $(p<0.05$, ANOVA), and trended to more fusion $(0.05<\mathrm{p}<0.10)$ than control animals and the group treated with 70:30 PLa cages containing autograft.

\section{Histological Evaluation}

For all cohorts at 3 months, fibroplasia was the principal histological feature (Fig. 3). Connective tissue was interposed between vertebral endplates, which in these

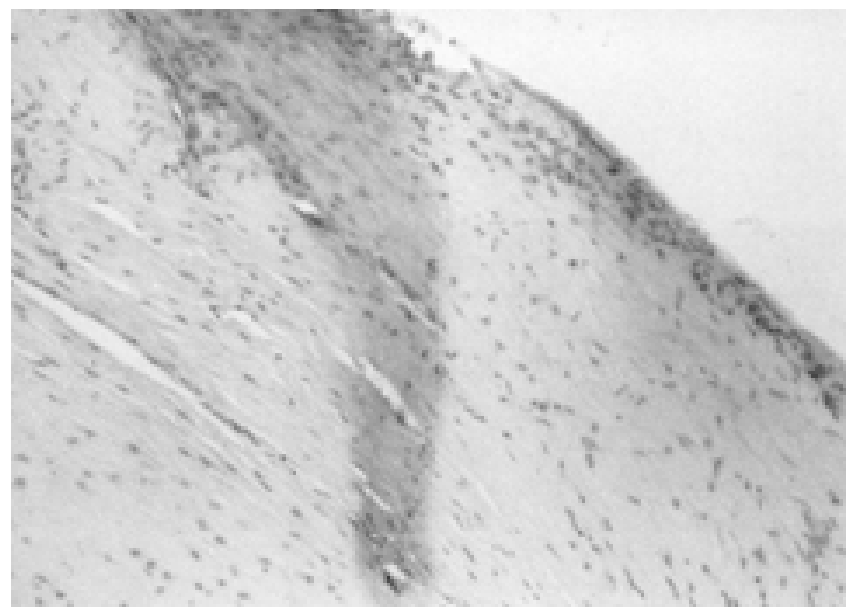

Fig. 3. Photomicrograph showing fibrous response to the implant. The empty space at the upper right remains after the solid 70:30 PLDLLA/PGA cage was removed. Only a muted inflammatory response is present adjacent to where the cage was located. A brightly stained fibrous response was the principal reaction in spinal tissue obtained in all cohorts killed 3 months after treatment. $\mathrm{H} \& \mathrm{E}$, original magnification $\times 100$. cases prevented development of a solid bone union. This deposit was composed of fibrous tissue surrounded by numerous macrophages, epithelioid cells, scattered lymphocytes, and rare multinucleated giant cells. Underlying this tissue was new bone, which had formed along the endplates of each interspace peripheral to the fibrous tissue. Osteoid was deposited around bone trabeculae and islets of calcifying cartilage, mostly peripheral to the fibrous tissue, outside the cages. The 70:30 cages were intact; there were a few solid remnants of the 85:15 cages remaining in the interspaces, but no functional fragments. A scant inflammatory reaction was noted adjacent to the cages and their remnants, which were solidly incorporated into the surrounding tissue. The cages and their remnants had to be manually removed from the tissue before it could be prepared for histological analysis.

The histological pattern was different in animals examined at 6 months. In the animals whose interspaces were treated using tricortical autograft, copolymer cages (both 85:15 and 70:30) filled with autograft, and 85:15 cages filled with rhBMP-2, there was quantitatively less fibrous tissue, and increased bone formation, than was found in the animals killed at 3 months (Fig. 4). The new bone was growing from both vertebral endplates. Again, osteoid was deposited around bone trabeculae and islets of calcifying cartilage, but hypertrophic osteoblasts were found surrounding long spicules of bone. In the cohort of animals that underwent fusion with 70:30 cages and rhBMP-2, the primary histological reaction was of a fibrocartilaginous bone union extending from the superior to the inferior bone ridge, both inside and outside the cage (Fig. 5). Again, the 70:30 cages were intact, whereas there were no remnants of the $85: 15$ cages.

Despite the increased amount of bone formation in these latter groups, the mean histological grade of new bone formation was similar and not significantly different

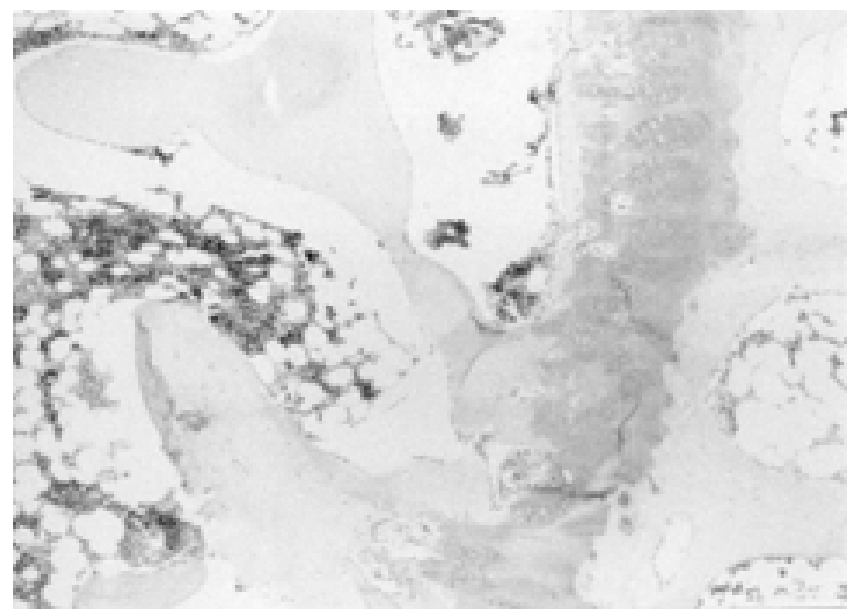

Fig. 4. Photomicrograph showing an implanted 85:15 PLDLLA/PGA cage filled with autograft bone. At the far left and right, darkly stained, vacuolized cage breakdown products are present directly adjacent to newly formed lighter-stained bone trabeculae, indicating that these two tissues can coexist. New bone is seen between the trabeculae. The cage is in the process of being resorbed, and no solid remnants are present. $\mathrm{H} \& \mathrm{E}$, original magnification $\times 40$. 


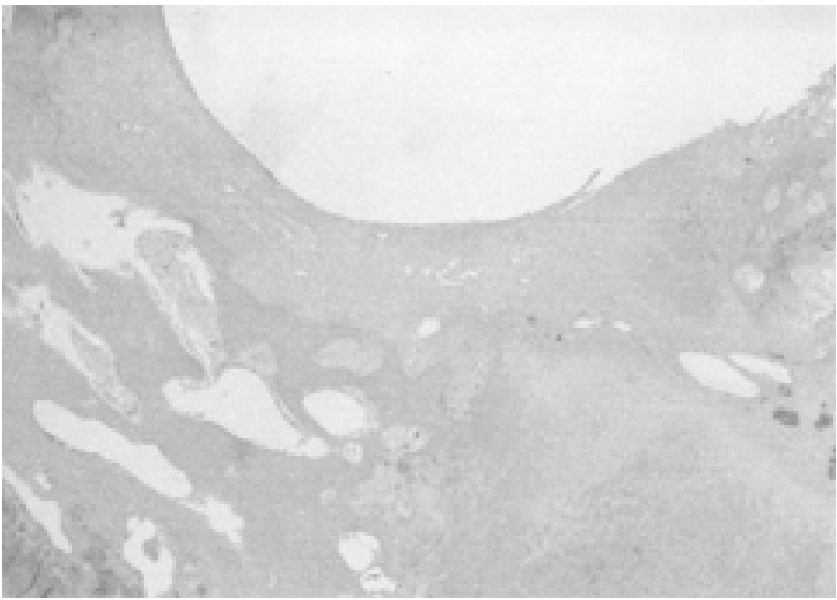

Fig. 5. Photomicrograph showing an implanted 70:30 PLDLLA/PGA cage filled with rhBMP-2. The cage was still present and solid when this spine was processed, and the device was removed before histological treatment. The empty space at the top is where the cage was located. A muted inflammatory response is present at the far right, adjacent to where the cage was located. New bone is observed immediately adjacent to the cage. $\mathrm{H} \& \mathrm{E}$, original magnification $\times 40$.

between the animals killed at 3 and 6 months, which ranged from 1.3 to 2 (the complete results are described in Tables 2 and 3). Only the cohort that underwent fusion with 70:30 PLDLLA/PGA cages filled with rhBMP-2 (Fig. 6) and killed at 6 months had a significantly higher grade $(2.6 \pm 0.5)$ than that of the controls or other animal groups ( $\mathrm{p}<0.05$, ANOVA).

In interspaces in which a solid union was found, bone trabeculae were noted both inside and outside cage confines. The presence of some inflammatory reaction near cages and their breakdown products did not limit this bone growth.

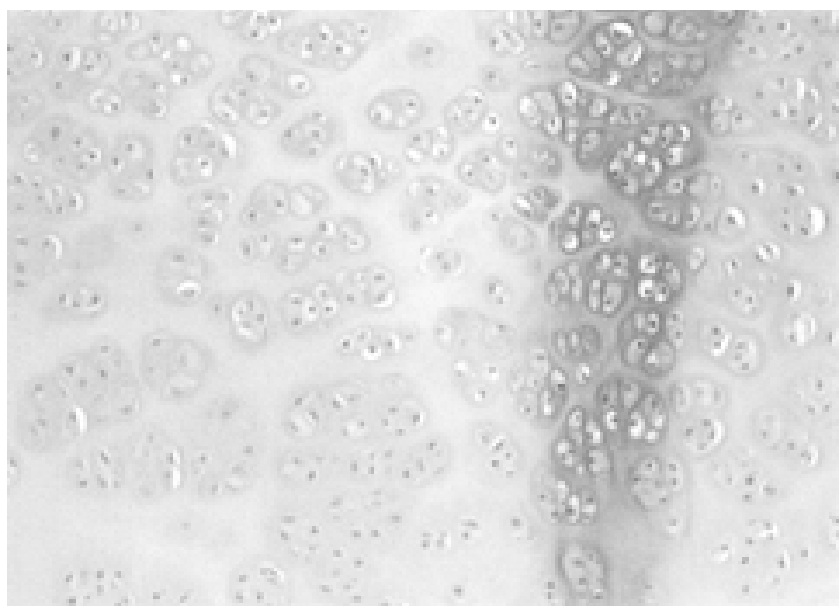

Fig. 6. Photomicrograph showing an implanted 70:30 PLDLLA/PGA cage filled with rhBMP-2. Significantly greater amounts of new bone were laid down in the presence of rhBMP-2. H \& E, original magnification $\times 100$.

\section{Composite Grade}

A stable intervertebral union is indicated by a composite grade of 7 , whereas degrees of fibrous or incomplete union are indicated by grades of 1 through 6 , and a grade of 0 indicates a nonunion. As expected from our previous study, no animal had attained a solid fusion 3 months after treatment. At 3 months, one (14\%) of seven of the control interspaces was judged to have a stable union, wheras none of the other interspaces had a union. The mean composite grade for all five cohorts was between 3.1 and 3.8, with no significant differences (Table 2). At 6 months, one of seven control interspaces was judged to be rigid (Grade 2 ) on manual inspection, to be connected by a new osseous intervertebral bridge (Grade 2) on radiographic studies, and to have marked new bone formation (Grade 3) on histological investigations, for a composite grade of 7. That interspace had successfully arthrodesed, and was bridged by bone without intervening soft tissues or inflammation.

Of the interspaces fused with cages filled with autograft, three $(30 \%)$ of 10 of the spines treated with $85: 15$ devices were graded 7, whereas none of the spines treated with 70:30 PLDLLA/PGA cages were graded 7. Of the interspaces treated with cages filled with rhBMP-2, none of the spines treated with 85:15 PLDLLA/PGA cages were graded 7, whereas five $(63 \%)$ of eight of the spines treated with 70:30 cages were graded 7. A union consisting primarily of bone stabilized each of the five cageimplanted interspaces graded 7. The mean combined grade at 6 months showed no significant differences between any of the cohorts, whose grades ranged from 3 to 4.6 (Table 3), except for the graph treated with 70:30 cages filled with rhBMP-2, which the goats had a mean composite grade of $6.3 \pm 1.2(p<0.05$, ANOVA $)$.

\section{DISCUSSION}

Degradation of both PGA and PLA occurs through nonspecific hydrolytic cleavage of their ester bonds. ${ }^{1}$ As it breaks down, PGA is degraded into glycolic acid and glyoxylic acid, which may be excreted in the urine, or further converted to glycine, then to serine, and finally to pyruvic acid, which enters the tricarboxylic acid cycle, and is excreted as water and carbon dioxide. ${ }^{17}$ Although PGA is degraded rapidly, in approximately 2 to 4 months, PLA degradation, in contrast, takes several years. ${ }^{28}$ As it breaks down, PLA is degraded to lactic acid, which is further converted to pyruvic acid, and again enters the tricarboxylic acid cycle. The rapid absorption of PGA has been noted to be the cause of the stronger inflammatory response observed with this material as opposed to PLA. ${ }^{14}$

The absorption rate of biopolymers is influenced by multiple factors. The ratio of the different polymers and stereoisomers in each compound has a profound effect on the absorption rate. ${ }^{2}$ In mixed PLA/PGA implants, decreasing the amount of PLA will (counterintuitively) tend to increase the degradation rate. ${ }^{8}$ The polylactides have the capacity to be molded into various shapes and sizes, ${ }^{2}$ which can also significantly affect the degradation rate. ${ }^{25}$ A higher surface/volume ratio of a biodegradable construct will result in more rapid degradation. ${ }^{39}$ Thus, a 
screw, with a higher surface/volume ratio, will be absorbed faster than an interbody device made of the same material. The relative environment will also significantly affect the absorption of such devices. Faster degradation rates have been found in liquid environments and at higher temperatures. ${ }^{9}$ Materials have sometimes been found to absorb faster in vivo than results of in vitro studies had led one to expect. ${ }^{41}$ The process by which the implantable device is manufactured and sterilized may also influence the absorption rate..$^{916}$ In previous studies it has been reported that bone can be formed in both nonspinal ${ }^{4,5,12,37}$ and spinal applications. ${ }^{2,15,20,24,34,40}$ Thus, osteogenesis can occur in the acidic environment created by the breakdown of these polymers.

In this study, placement of a bioabsorbable cage filled with either autograft or rhBMP-2 led to similar stable interbody union rates as in interspaces fused with tricortical autograft. In contrast to the bone fusion elicited by the autograft, the cages initially elicited a primarily fibrous response at 3 months after implantation, with minimal new bone deposit at the periphery of the fibrous mass. At 6 months after implantation, the fibrous mass was being replaced by new bone, which was growing into the interspace from both vertebral bodies. This bone fusion was occurring both inside and outside the cage, indicating that an initial fibrous union will not necessarily prevent a final bone union from occurring. The 70:30 PLDLLA/PGA cages filled with rhBMP-2 elicited more bone tissue in the fusion histologically than the other cohorts, and also led to a stronger fusion mass than in the other cohorts, including the controls. Bone morphogenetic protein has been previously shown to lead to a stronger, more rapid fusion than in controls when titanium cages are used:42 our results indicate that this is true when rhBMP-2 is used with more slowly dissolving cages as well. None of the cages extruded, despite the fact that no orthoses were used, nor was internal fixation, and the goats engaged in head-butting activity. Nevertheless, this activity may account for why our fusion rates are lower than reported previously in the literature. ${ }^{43}$

Further studies are needed to determine if these cages are suitable for clinical use, but recent animal and clinical studies are promising. Toth, et al., ${ }^{34}$ studied HYDROSORB (70:30 PLLA/PDLLA) cages filled with autograft or rhBMP-2 that were implanted in the sheep lumbar spine, with follow-up durations of up to 24 months postsurgery. Biomechanical testing in their study revealed that the fused spines were stiffer than nonfused spines. Histological, radiographic, and Faxitron high-resolution radiographic studies revealed that bone fusion was occurring between the superior and inferior vertebrae through, anterior to, and sometimes posterior to the cage, and that eventually the separate fusion masses were extending through the anterior margins of the device, indicating that bone was replacing the degrading cage. There was a trend of increased fusion stiffness and of radiographically and histologically confirmed fusion over time. At 6 months, in two of four animals fusion was confirmed histologically, in four $(67 \%)$ of six it was confirmed at 1 year, and five $(100 \%)$ of five exhibited fusion at more than 1 year. Only a mild-to-moderate inflammatory response was present.

Wuisman, et al., ${ }^{41}$ studied PLLA interbody devices in goat lumbar spines, with a follow-up duration of 36 months. Their results showed that there is an increased rate of bone formation in the PLLA cages compared with titanium cages, indicating that there is stress shielding associated with those devices. The rate of bone formation was not constant: it increased when the PLLA cages began to degrade. The cages disintegrated at 1 year postsurgery, and were replaced by both bone and fibrous tissue. Of all the animals followed for 1 year or longer, 15 $(88 \%)$ of 17 goats treated with PLLA cages had a bone fusion, whereas only $2(66 \%)$ of three of those that underwent treatment with titanium cages attained adequate fusion. The difference was significant. All cages had disintegrated at 12 months, and were completely gone at 24 months. A mild inflammatory response was seen, which had disappeared by 36 months.

Van Dijk, et al., ${ }^{38}$ studied PLLA cages used to treat goat lumbar spine, and followed up for 3 years. They found that $19(86 \%)$ of the 22 spines treated with the PLLA cages appeared to be fused on radiographic studies, which was a significantly higher rate than the two (33\%) of six spines that attained fusion with titanium cages. The PLLA cages disintegrated at 12 months postsurgery, and the disintegrating cages were found to be partially replaced by trabecular bone.

This study is, besides our initial pilot study, ${ }^{8}$ the only one to address the use of biodegradable cages in the goat cervical spine. In the pilot study, we evaluated 85:15 PLDLLA/PGA cages packed with autograft bone, and found that at 12 weeks postsurgery, a primarily fibrous, yet stable union had formed. We concluded that the use of bioabsorbable materials held promise, but that a cage producing less of an inflammatory reaction might be more suited for internal spinal fixation. In this study, we used cages composed of 70:30 PLDLLA/PGA, which has been shown to elicit a smaller immune response. We found that the fusions were initially fibrous, but at the 6-month follow-up review the fibrous tissue was replaced by spicules of bone. Fusion was occurring both within and anterior to the cage. There was no sign of cage degradation at 6 months, and a minimal inflammatory response was present. There were no cage extrusions, and no signs of infection or other sequelae as a result of the use of these cages.

Future studies should follow the animals for a longer period to determine when the cages degrade. Because the 70:30 PLDLLA/PGA cages are still intact 12 months after placement, future studies should be continued beyond that point. Histological and radiographic studies should examine where bone union occurs: inside the cage, outside the cage, or both. Further investigations should examine whether the spaces left by cage degradation are filled in by bone or fibrous tissue, or if permanent voids are left between fused vertebrae. Biomechanical testing performed at various stages after cage implantation would be used to evaluate how strong the treated spine is over time.

Our findings indicate that the short-term union results of bioabsorbable cages in the goat cervical spine are similar to those seen when tricortical iliac crest autograft is used. These cages supplied sufficient stability to the spine during the load-bearing period immediately postsurgery; in all treated cohorts the results of histological, radiographic, and manual strength testing were similar to or 
higher than in the control animals, and there were similar or higher rates of final interbody fusion.

In this pilot study we demonstrated the feasibility of using bioabsorbable cages in the cervical spine for anterior arthrodesis and interbody fusion after discectomy.

\section{SUMMARY OF FINDINGS}

The 85:15 PLDLLA/PGA cages resorb too quickly to be functionally useful, whereas the 70:30 cages are still functionally intact and unresorbed at 6 and 12 months postimplantation. There is relatively little inflammatory response to the intact cages. There is some inflammatory response to the degradation products of disintegrating cages, but it appears to be clinically insignificant. Bone will grow in the presence of the cages and their breakdown products. The rhBMP-2 appears to be functional in the presence of the cages and their breakdown products, and may even lead to superior arthrodesis than autologous bone.

Future studies must address when and how 70:30 PLDLLA/PGA cages resorb. Biomechanical studies will address the stability and mechanics of the cages at implantation, and at various times thereafter. Results of histological and microradiographic analysis will determine whether and when the voids left by cage resorption are filled in with bone or inflammatory tissue. Finally, the 70:30 bioabsorbable cage must be compared with more recently reported cervical polymeric devices. Ultimately, future studies in this field must address whether bioabsorbable devices offer any clinically significant advantages over nonresorbing polymeric devices and traditional metal devices for interbody fusion, and if so, which polymer in what configuration is best.

\section{CONCLUSIONS}

There are numerous theoretical advantages in using a bioabsorbable cage in the cervical spine after discectomy. Radiolucency allows for better evaluation of arthrodesis on follow-up images, and does not interfere with or preclude the use of computerized tomography or magnetic resonance imaging studies to evaluate the spine in future investigations. By adjusting the composition of such devices, it should be possible to develop an implant that would provide immediate stability to the spine after surgery, but would slowly dissolve, allowing the spine to take on more weight, and preventing stress shielding and subsequent fusion failure. These devices would reduce the long-term risks of hardware extrusion, and thus reduce risks to adjacent organs and the need for surgery to remove hardware.

These devices must be subjected to the same controlled comprehensive evaluations given to titanium devices. They should be tested biomechanically, radiographically, microradiographically, and histologically in animal and cadaveric spines at various intervals after implantation to evaluate their strength, the adequacy of bone fusion, and the extent of inflammatory reactions. Only after these devices are better understood quantitatively based on investigations conducted in animals in vivo and in cadaveric models in vitro, should clinical studies begin.

\section{Dedication}

This paper is dedicated to the memory of Dr. David W. Cahill, who was a colleague, mentor, and friend.

\section{References}

1. Agrawal CM, Niederauer GG, Micallef DM, et al: The use of PLA-PGA polymers in orthopedics, in Wise DL, Trantolo DJ, Altobelli DE, et al (eds): Encyclopedic Handbook of Biomaterials and Bioengineering. Part B: Applications. New York: Marcell Dekker, 1995, Vol 1, pp 1055-1092

2. Alexander JT, Branch CL Jr, Subach BR, et al: Applications of a resorbable interbody spacer via a posterior lumbar interbody fusion technique. Orthopedics 25 (Suppl 10):S1185-S1189, 2002

3. Ames CP, Crawford NR, Chamberlain RH, et al: Feasibility of a resorbable anterior cervical graft containment plate. Orthopedics 25 (Suppl 10):S1149-S1155, 2002

4. Ashammakhi N, Makela EA, Vihtonen K, et al: The effect of absorbable self-reinforced polyglycolide membrane on metaphyseal bone. An experimental study on rats. Ann Chir Gynaecol 83:328-334, 1994

5. Ashammakhi N, Makela EA, Vihtonen K, et al: Effect of selfreinforced polyglycolide membranes on cortical bone: an experimental study on rats. J Biomed Mater Res 29:687-694, 1995

6. Austin RC, Branch CL Jr, Alexander JT: Novel bioabsorbable interbody fusion spacer-assisted fusion for correction of spinal deformity. Neurosurg Focus 14 (1):Article 11, 2003

7. Bucholz RW, Henry S, Henley MB: Fixation with bioabsorbable screws for the treatment of fractures of the ankle. J Bone Joint Surg Am 76:319-324, 1994

8. Cahill DW, Martin GJ Jr, Hajjar MV, et al: Suitability of bioresorbable cages for anterior cervical fusion. J Neurosurg (Spine 2) 98:195-201, 2003

9. Claes LE, Ignatius AA, Rehm KE, et al: New bioresorbable pin for the reduction of small bony fragments: design, mechanical properties and in vitro degradation. Biomaterials 17: 1621-1626, 1996

10. Cohen SR, Holmes RE, Amis P, et al: Internal craniofacial distraction with biodegradable devices: early stabilization and protected bone regeneration. J Craniofac Surg 11:354-366, 2000

11. Cordewener FW, Bos RR, Rozema FR, et al: Poly(L-lactide) implants for repair of human orbital floor defects: clinical and magnetic resonance imaging evaluation of long-term results. J Oral Maxillofac Surg 54:9-14, 1996

12. Cornwall GB, Thomas KA, Turner AS, et al: Use of a resorbable sheet in iliac crest reconstruction in a sheep model. Orthopedics 25 (Suppl 10):S1167-S1171, 2002

13. Cunningham BW, Orbegoso CM, Dmitriev AE, et al: The effect of titanium particulate on development and maintenance of a posterolateral spinal arthrodesis: an in vivo rabbit model. Spine 27:1971-1981, 2002

14. Cutright DE, Hunsuck EE: Tissue reaction to the biodegradable polylactic acid suture. Oral Surg Oral Med Oral Pathol 31: 134-139, 1971

15. DiAngelo DJ, Kitchel S, McVay BJ, et al: Bioabsorbable anterior lumbar plate fixation in conjunction with anterior interbody fusion cages. Orthopedics 25 (Suppl 10):S1157-S1165, 2002

16. Gogolewski S, Mainil-Varlet P: Effect of thermal treatment on sterility, molecular and mechanical properties of various polylactides. 2. Poly(L/D-lactide) and poly(L/DL-lactide). Biomaterials 18:251-255, 1997

17. Hollinger JO, Battistone GC: Biodegradable bone repair materials. Synthetic polymers and ceramics. Clin Orthop 207: 290-305, 1986

18. Hovis WD, Bucholz RW: Polyglycolide bioabsorbable screws in the treatment of ankle fractures. Foot Ankle Int 18:128-131, 1997 
19. Hovis WD, Kaiser BW, Watson JT, et al: Treatment of syndesmotic disruptions of the ankle with bioabsorbable screw fixation. J Bone Joint Surg Am 84-A:26-31, 2002

20. Kandziora F, Pflugmacher R, Kleemann R, et al: Biomechanical analysis of biodegradable interbody fusion cages augmented with poly(propylene glycol-co-fumaric acid). Spine 27: 1644-1651, 2002

21. Kaptain GJ, Vincent DA, Laws ER Jr: Cranial base reconstruction after transsphenoidal surgery with bioabsorbable implants. Neurosurgery 48:232-234, 2001

22. Kulkarni RK, Moore EG, Hegyeli AF, et al: Biodegradable poly(lactic acid) polymers. J Biomed Mater Res 5:169-181, 1971

23. Kulkarni RK, Pani KC, Neuman C, et al: Polylactic acid for surgical implants. Arch Surg 93:839-843, 1966

24. Lowe TG, Coe JD: Bioresorbable polymer implants in the unilateral transforaminal lumbar interbody fusion procedure. Orthopedics 25 (Suppl 10):S1179-S1183, 2002

25. Mainil-Varlet $\mathrm{P}$, Rahn B, Gogolewski S: Long-term in vivo degradation and bone reaction to various polylactides. 1 . Oneyear results. Biomaterials 18:257-266, 1997

26. McAfee PC, Cunningham BW, Lee GA, et al: Revision strategies for salvaging or improving failed cylindrical cages. Spine 24:2147-2153, 1999

27. McAfee PC, Farey ID, Sutterlin CE, et al: 1989 Volvo Award in basic science. Device-related osteoporosis with spinal instrumentation. Spine 14:919-926, 1989

28. Miller RA, Brady JM, Cutright DE: Degradation rates of oral resorbable implants (polylactates and polyglycolates): rate modification with changes in PLA/PGA copolymer ratios. J Biomed Mater Res 11:711-719, 1977

29. Ohlin A, Karlsson M, Duppe H, et al: Complications after transpedicular stabilization of the spine. A survivorship analysis of 163 cases. Spine 19:2774-2779, 1994

30. Poynton AR, Tomin E, Cornwall GB, et al: Resorbable posterolateral graft containment in a rabbit spinal fusion model. Orthopedics 25 (Suppl 10):S1173-S1177, 2002

31. Serlo W, Ashammakhi N, Tormala P, et al: A new technique for correction of trigonocephaly in an infant: application of an absorbable endocranial plate. Childs Nerv Syst 16:595-597, 2000

32. Serlo W, Ashammakhi N, Tormala P, et al: A new technique for cranial bone osteofixation: use of bioabsorbable tacks and plates to fix parietal bone split grafts used for reconstruction of a posttraumatic frontal bone defect. J Craniofac Surg 13: 331-336, 2002

33. Shafer BL, Simonian PT: Broken poly-L-lactic acid interference screw after ligament reconstruction. Arthroscopy 18:E35, 2002

34. Toth JM, Wang M, Scifert JL, et al: Evaluation of 70/30 D,L$\mathrm{PLa}$ for use as a resorbable interbody fusion cage. Orthopedics 25 (Suppl 10):S1131-S1140, 2002

35. Vaccaro AR, Madigan L: Spinal applications of bioabsorbable implants. Orthopedics 25 (Suppl 10):S1115-S1120, 2002

36. Vaccaro AR, Venger BH, Kelleher PM, et al: Use of a bioabsorbable anterior cervical plate in the treatment of cervical degenerative and traumatic disk disruption. Orthopedics 25 (Suppl 10):S1191-S1199, 2002

37. van der Elst M, Bramer JA, Klein CP, et al: Biodegradable interlocking nails for fracture fixation. Clin Orthop 357: 192-204, 1998

38. van Dijk M, Smit TH, Burger EH, et al: Bioabsorbable poly-Llactic acid cages for lumbar interbody fusion: three-year followup radiographic, histologic, and histomorphometric analysis in goats. Spine 27:2706-2714, 2002

39. Wang Y: Resorbable Buffered Internal Fixation Devices. Thesis. Boston: Northeastern University, 1997, p 75

40. Welch WC, Cornwall GB, Toth JM, et al: Use of polylactide resorbable film as an adhesion barrier. Orthopedics 25 (Suppl 10):S1121-S1130, 2002

41. Wuisman PJ, van Dijk M, Smit TH: Resorbable cages for spinal fusion: an experimental goat model. Orthopedics 25 (Suppl 10):S1141-S1148, 2002

42. Zdeblick TA, Ghanayem AJ, Rapoff AJ, et al: Cervical interbody fusion cages. An animal model with and without bone morphogenetic protein. Spine 23:758-766, 1998

43. Zdeblick TA, Wilson D, Cooke ME, et al: Anterior cervical discectomy and fusion. A comparison of techniques in an animal model. Spine 17:S418-S426, 1992

Manuscript received January 15, 2004.

Accepted in final form February 10, 2004.

Address reprint requests to: Caleb R. Lippman, M.D., 211 East Ohio Street, Apartment 2421, Chicago, Illinois 60611. email: caleb.lippman@ mssm.edu. 